\title{
Aspartyl Peptidase
}

National Cancer Institute

\section{Source}

National Cancer Institute. Aspartyl Peptidase. NCI Thesaurus. Code C28411.

Aspartyl Proteases (Aspartic Endopeptidases) have an acidic residue (aspartate) involved in the catalytic process, have a pH optimum below 5 and catalyze the cleavage of internal peptide bonds in a polypeptide or protein. 